\title{
Doctor of Pharmacy
}

National Cancer Institute

\section{Source}

National Cancer Institute. Doctor of Pharmacy. NCI Thesaurus. Code C39386.

A professional, postgraduate degree that requires completion of a program in pharmacy that meets all of the following criteria: completion of the academic requirements to beg in practice in the profession; at least 2 years of college work prior to entering the program; eight academic semesters after admission to the School of Pharmacy that involve extensive instruction in professional pharmacy pre-clinical and clinical sciences. 